\title{
An Optimal Current Distribution Method of Dual-Rotor BLDC Machines
}

\author{
Sung-Jung Kim*, Je-Wook Park ${ }^{* *}$, Won-Sang Im ${ }^{* *}$, Hyun-Woo Jung ${ }^{*}$, and Jang-Mok Kim ${ }^{\dagger}$ \\ *LG Electronics, Changwon, Korea \\ ${ }^{* * \dagger}$ Dept. of Electrical Eng., Pusan National University, Busan, Korea
}

\begin{abstract}
This paper proposes an optimal current distribution method of dual-rotor brushless DC machines (DR-BLDCMs) which have inner and outer surface-mounted permanent-magnet rotors. The DR-BLDCM has high power density and high torque density compare to the conventional single rotor BLDCM. To drive the DR-BLDCM, dual 3-phase PWM inverters are required to excite the currents of a dual stator of the DR-BLDCM and an optimal current distribution algorithm is also needed to enhance the system efficiency. In this paper, the copper loss and the switching loss of a DR-BLDCM drive system are analyzed according to the motor parameters and the switching frequency. Moreover, the optimal current distribution method is proposed to minimize the total electrical loss. The validity of the proposed method was verified through several experiments.
\end{abstract}

Key words: Copper loss, DR-BLDCM, Stator- resistance ratio, Switching loss, Torque-constant ratio

\section{INTRODUCTION}

Dual-rotor electric machines have been studied in many literatures to obtain high torque density and high efficiency [1]-[5]. Especially, the high torque density is the essential characteristic of the in-wheel motor because the poor hill climbing ability is the major disadvantage of electric vehicles (EVs) and E-scooters [6]-[9]. In this paper, a dual-rotor brushless DC machine (DR-BLDCM) is implemented to the in-wheel motor of the E-scooter. Fig. 1 shows the structure of the DR-BLDCM. The DR-BLDCM is constructed with two concentric machines which have inner and outer surface-mounted permanent-magnet rotors and the dual-stator is located between the outer and the inner rotors.

To control the DR-BLDCM, appropriate currents must be excited to each stator. In this paper, an optimal current distribution method of the DR-BLDCM is proposed. Considering the torque-constant ratio and the stator-resistance ratio of the inner and outer motors, the currents for each stator are optimally distributed according to the torque command for the minimum electrical loss. The validity of the proposed method is verified through loss analysis and the several experiments.

Manuscript received Aug. 16, 2012; revised Nov. 21, 2012

Recommended for publication by Associate Editor Dong-Hee Lee.

${ }^{\dagger}$ Corresponding Author: jmok@pusan.ac.kr

Tel: +82-51-510-2366, Fax: +82-51-513-0212, Pusan National University

${ }^{*}$ LG Electronics, Changwon, Korea

${ }^{* *}$ Dept. of Electrical Eng., Pusan National University, Korea

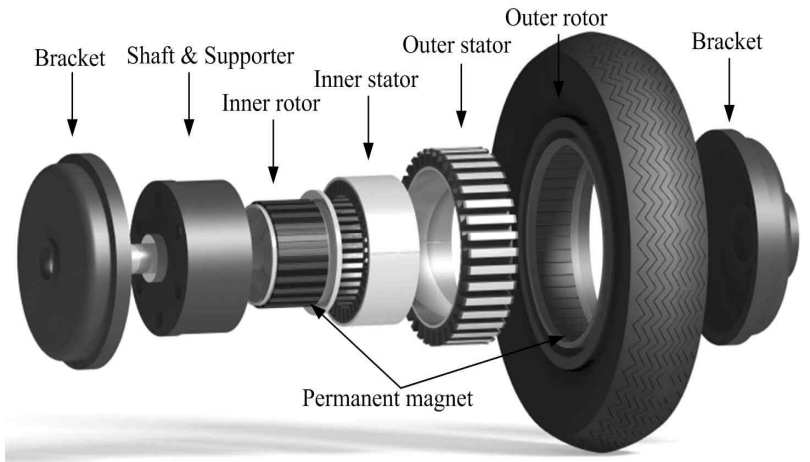

Fig. 1. Structure of the DR-BLDCM.

\section{CURRENT DISTRIBUTION METHOD FOR MINIMUM COPPER LOSS}

The total torque command of the DR-BLDCM can be transformed to phase current command because the phase current is proportional to the torque as shown in (1) [10].

$$
T_{e}=P k_{T} i^{*}
$$

where $T_{e}$ is the torque, $P$ is the number of poles and $k_{T}$ is the torque constant.

Thus, the total torque of the DR-BLDCM can be expressed as (2).

$$
T=T_{\text {outer }}+T_{\text {inner }}=P\left(k_{t_{-} \text {outer }} i_{\text {outer }}^{*}+k_{t_{-} \text {inner }} i_{\text {inner }}^{*}\right)
$$




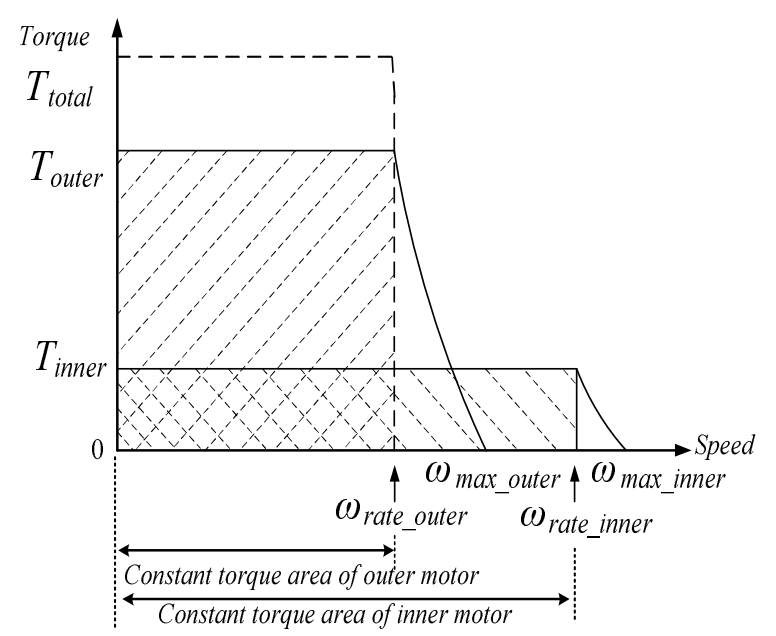

Fig. 2. Torque/Speed curve of the DR-BLDCM.

where $T_{\text {outer }}$ and $T_{\text {inner }}$ are torques, $k_{t_{-} \text {outer }}$ and $k_{t_{-} \text {inner }}$ are torque constants and $i_{\text {outer }}^{*}$ and $i_{\text {inner }}^{*}$ are phase current reference of the outer and the inner rotor respectively.

Because $k_{t_{-} \text {outer }}$ and $k_{t_{-} \text {inner }}$ are not the same, the torque-speed curves of the outer and the inner motors are different as shown in Fig. 2.

There are numerous combinations of $i_{\text {outer }}^{*}$ and $i_{\text {inner }}^{*}$ for the same torque. Therefore, the optimal current distribution method has to be derived to minimize the copper loss while driving the DR-BLDCM, by considering the torque constant and the stator resistance.

The torque constant ratio and the phase resistor ratio can be defined as (3) and (4).

$$
\begin{aligned}
& \alpha=k_{t_{-} \text {outer }} / k_{t_{-} \text {inner }} \\
& \beta=R_{\text {outer }} / R_{\text {inner }}
\end{aligned}
$$

where $R_{\text {outer }}$ and $R_{\text {inner }}$ are phase resistances of the inner and outer motor, respectively.

To obtain the same torque with the single mode operation while driving the dual mode operation, the current reference must be distributed as (5).

$$
T=P k_{t_{-} \text {outer }} i^{*}=P k_{t_{-} \text {outer }}\left(i_{\text {outer }}^{*}+i_{\text {inner }}^{*} / \alpha\right)
$$

From (5), the outer current can be expressed as (6).

$$
i_{\text {outer }}^{*}=i^{*}-i_{\text {inner }}^{*} / \alpha
$$

While driving the DR-BLDCM in the $120^{\circ}$ conduction mode, the total copper loss can be expressed as (7).

$$
P_{c u}=\left(i_{\text {outer }}^{*}\right)^{2} 2 R_{\text {outer }}+\left(i_{\text {inner }}^{*}\right)^{2} 2 R_{\text {inner }}
$$

From (6) and (7), the copper loss of the dual-rotor operation can be expressed as (8).

$$
\begin{aligned}
& P_{\text {cu }}=\left\{\beta\left(i^{*}-i_{\text {inner }}^{*} / \alpha\right)^{2}+i_{\text {inner }}^{*}{ }^{2}\right\} 2 R_{\text {inner }} \\
& =\left[\left(\frac{\alpha^{2}+\beta}{\alpha^{2}}\right) \cdot\left(i_{\text {inner }}^{*}-\frac{\alpha \beta i^{*}}{\left(\alpha^{2}+\beta\right)}\right)^{2}+\left(\frac{\alpha^{2} \beta\left(i^{*}\right)^{2}}{\left(\alpha^{2}+\beta\right)}\right)\right] \cdot 2 R_{\text {inner }}
\end{aligned}
$$

Therefore, the optimal phase current of the inner motor for the minimum copper loss is (9), and the minimum copper loss at this current is (10).

$$
\begin{gathered}
i_{\text {inner }}^{*}=\left(\frac{\alpha \beta}{\alpha^{2}+\beta}\right) i^{*} \\
P_{c u}=\left(\frac{\alpha^{2} \beta}{\alpha^{2}+\beta}\right) i^{* 2} 2 R_{\text {inner }}
\end{gathered}
$$

From (6) and (9), the current reference of the outer motor can be obtained as (11).

$$
i_{\text {outer }}^{*}=\frac{\alpha^{2}}{\alpha^{2}+\beta} i^{*}
$$

Fig. 3(a) shows the copper losses of a specific DR-BLDCM in various torque commands if the resistance of the inner stator is the same with the resistance of the outer stator and $\alpha$ is 4 . If the inner motor current is distributed as (9), the copper loss can be minimized at the same torque as shown in Fig. 3(a). Fig. 3(b) shows the minimum copper loss curves of specific DR-BLDCMs which have $\beta=1.5, \beta=1$ and $\beta=4$, respectively. According to these curves, if $\beta$ is larger, more current must be injected at the inner motor to minimize the cooper loss.

\section{ESTIMATION OF OPTIMAL MODE CHANGE POINT}

\section{A. Switching Loss Analysis}

The switching losses must be considered to determine whether to drive the DR-BLDCM with the single mode operation or dual mode operation. The switching loss of MOSFETs is caused by the overlap of the drain-to-source voltage and drain current. Fig. 4(a) and (b) show the turn-on and turn-off waveform of MOSFETs.

According to Fig. 4, the turn-on and turn-off loss of MOSFETs can be expressed as (12) and (13), respectively,

$$
\begin{aligned}
& P_{s(o n)}=\frac{1}{2} V_{d s} i_{d s}\left(t_{s(o n)}\right) f_{s w} \\
& P_{s(o f f)}=\frac{1}{2} V_{d s} i_{d s}\left(t_{s(o f f)}\right) f_{s w}
\end{aligned}
$$




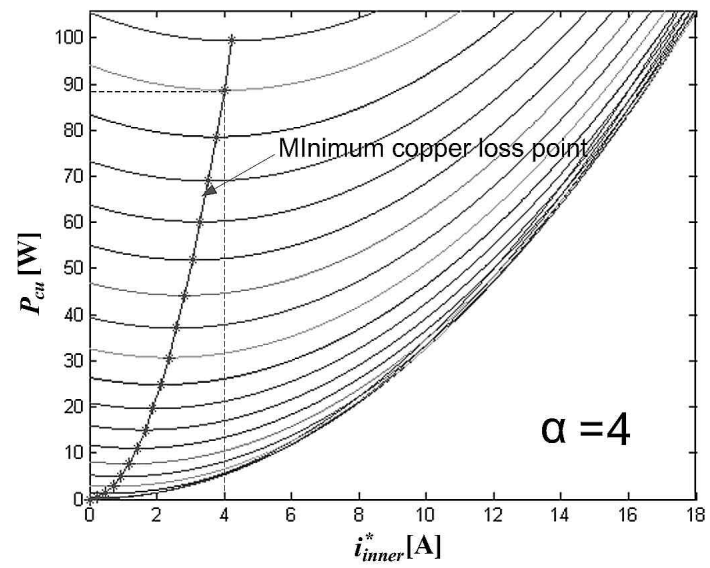

(a)

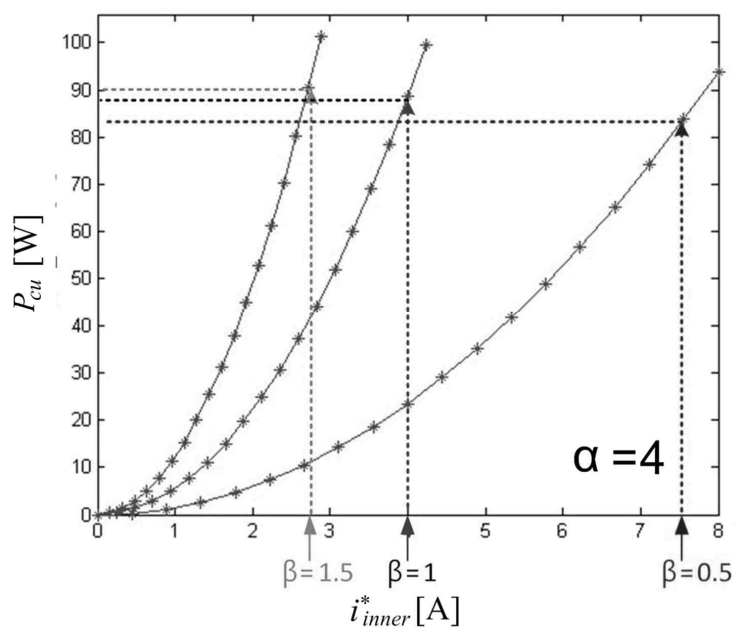

(b)

Fig. 3. Minimum copper loss point at the various torque command. (a) Minimum copper loss point when $\alpha=4$ and $\beta=1$. (b) Minimum copper loss point for the various $\beta$ when $\alpha=4$.

where $V_{d s}$ is the drain to source voltage of MOSFETs, $i_{d s}$ is the drain to source current of MOSFETs, $f_{s w}$ is the switching frequency, $t_{s(o n)}$ and $t_{s(o f f)}$ are turn-on and turn-off time of MOSFETs, respectively.

From (12) and (13), the switching loss of the single mode operation and the dual mode operation can be expressed as (14) and (15), respectively.

$$
\begin{gathered}
P_{s w s}=P_{s(o n)}+P_{s(o f f)}=\frac{1}{2} t_{\text {total }} V_{d s} f_{s w} i^{*} \\
P_{s w d}=P_{s(o n)}+P_{s(o f f)}=\frac{1}{2} t_{\text {total }} V_{d s} f_{s w}\left(\left(i^{*}-i_{\text {inner }}^{*} / \alpha\right)+i_{\text {inner }}^{*}\right)
\end{gathered}
$$

where, $t_{\text {total }}=t_{s(\text { on })}+t_{s(\text { off })}$.

The switching loss of the dual mode operation is larger than the single mode operation because the total current of the dual mode which is proportional to the switching loss is larger than of the single mode operation as shown in (16).

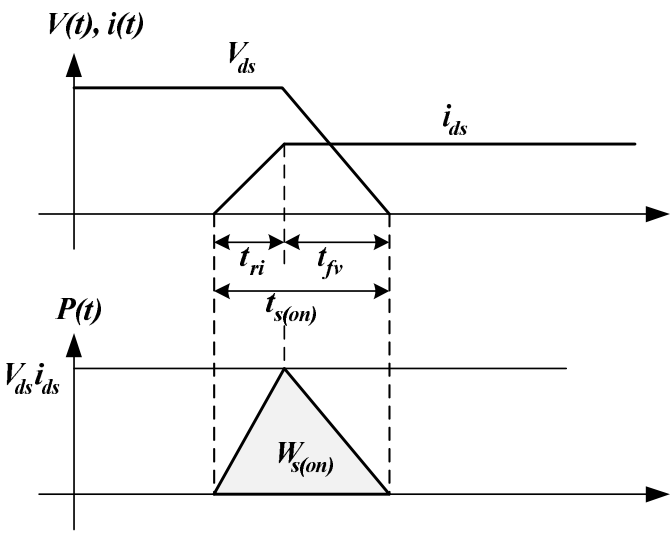

(a)

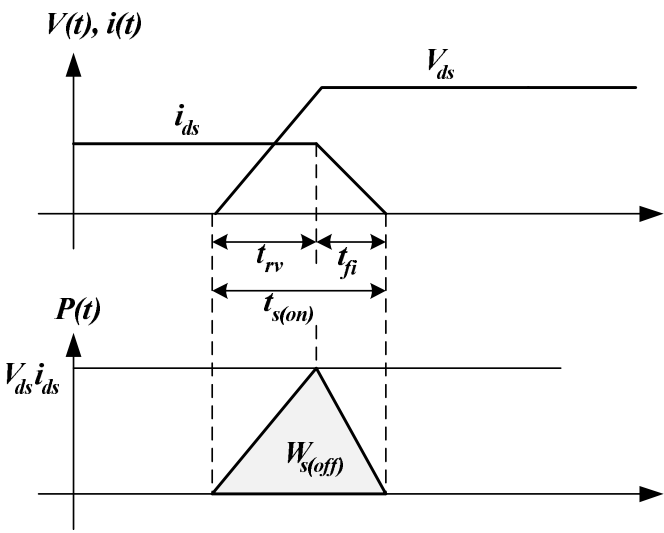

(b)

Fig. 4. Switching loss of MOSFET. (a) Turn-on loss of MOSFET. (b) Turn-off loss of MOSFET.

$$
i^{*}<\left(\left(i^{*}-i_{\text {inner }}^{*} / \alpha\right)+i_{\text {inner }}^{*}\right)
$$

\section{B. Optimal Mode Change Point}

For the high efficiency operation of the DR-BLDCM in the various torque commands, the optimal mode change point must be estimated. The mode change point can be determined by comparing the total loss of the single-mode operation and the dual-mode operation as (17) and (18).

$$
\begin{gathered}
P_{\text {total }(\sin g l e)}=\left(i^{*}\right)^{2} 2 R_{\text {outer }}+P_{\text {sws }} \\
P_{\text {total }(\text { dual })}=P_{c u}+P_{s w d}
\end{gathered}
$$

Fig. 5 shows the comparison of total electrical losses of the single and the dual mode operation when $\alpha$ is 4 . If the current reference which is the output of the speed controller is lower than the optimal mode change point, the total electrical loss of the dual mode is lower than the single mode operation.

Fig. 6 shows the block diagram of the proposed current distribution method for the DR-BLDCM. The output of the speed controller is the current reference $i^{*}$ that determines whether to drive DR-BLDCM with the single mode or dual mode, according to (17) and (18). In the dual mode operation, the current reference of the inner and the outer motors can be distributed as (9) and (11). 


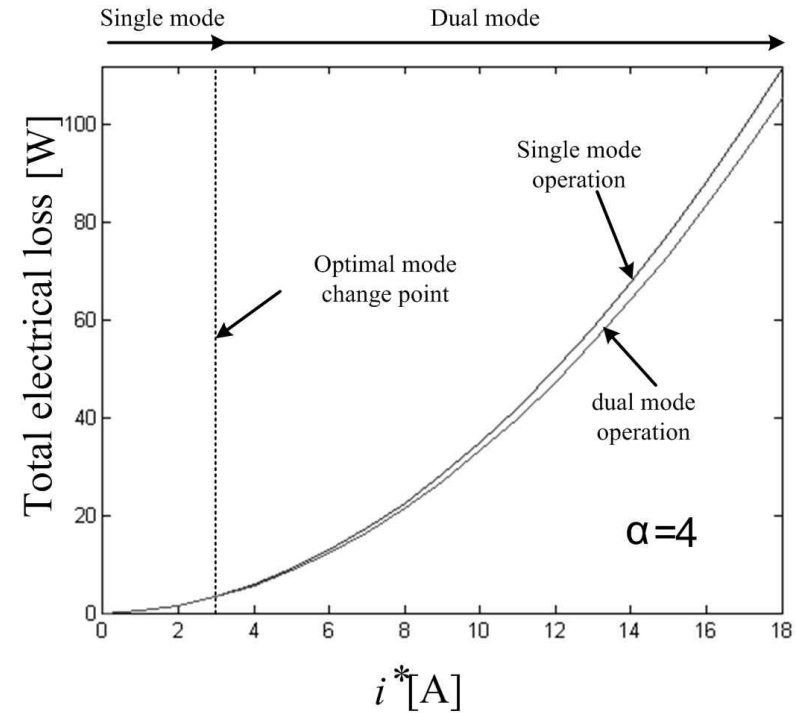

Fig. 5. Comparison of the total electrical losses of the single mode and the dual mode operation.

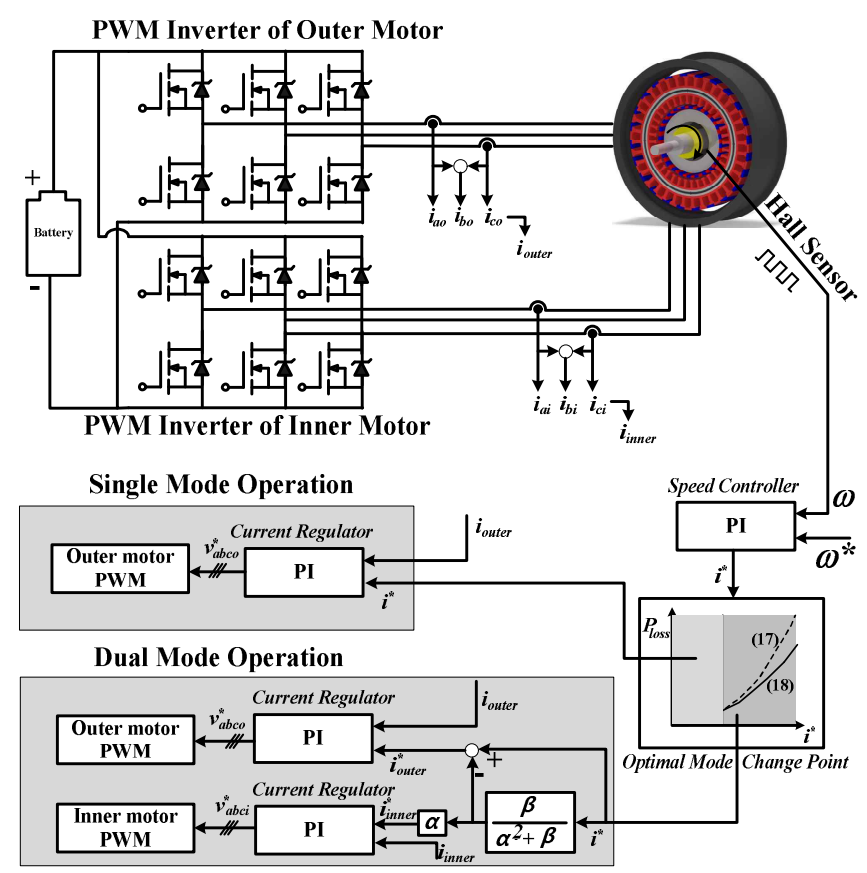

Fig. 6. Block diagram of the proposed current distribution method for DR-BLDCM.

\section{EXPERIMENTAL RESULTS}

The specifications of the implemented DR-BLDCM are listed in Table I. Fig. 7 shows the experimental equipment and the back-EMF waveforms of the DR-BLDCM. As shown in the Table I and Fig. 7(b), the torque constant of the outer motor is quadruple of the inner motor. The entire drive system is controlled by a digital signal processor (DSP), TMS320C28346, and the sampling period of the current
TABLE I

SPECIFICATIONS OF DR-BLDCM

\begin{tabular}{|c|c|c|}
\hline & Outer motor & Inner motor \\
\hline Rated power(W) & $\mathbf{1 , 2 0 0}$ & 300 \\
\hline Rated speed(RPM) & $\mathbf{3 6 0}$ & $\mathbf{3 6 0}$ \\
\hline Number of Poles & 48 & 48 \\
\hline Torque constant(Nm/A) & $\mathbf{0 . 4 7}$ & $\mathbf{0 . 1 1}$ \\
\hline Phase resistance( $\mathbf{\Omega})$ & $\mathbf{0 . 2}$ & $\mathbf{0 . 1 3}$ \\
\hline
\end{tabular}

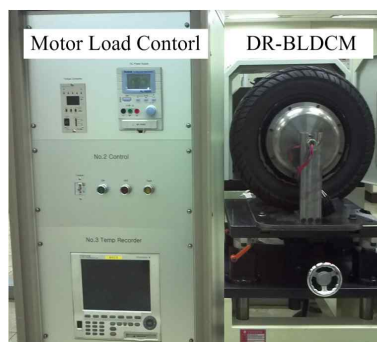

(a)

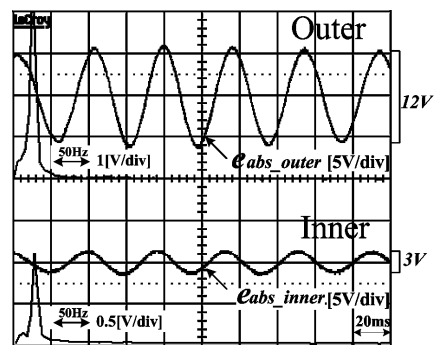

(b)
Fig. 7. Experimental equipments and the back-EMF waveforms of DR-BLDCM. (a) DR-BLDCM and the load controller. (b) Back-EMF waveforms of DR-BLDCM.

regulator is $100 \mu \mathrm{s}$. The motor speed is $360 \mathrm{rpm}$. The electrical power loss is calculated by measuring the input and output power of the PWM inverter and the output power of the DR-BLDCM with the power analyzer and the dynamometer.

Fig. 8 shows the copper losses of the DR-BLDCM according to the current reference of the inner motor at various load conditions. The outer motor is controlled with a speed controller to maintain $360 \mathrm{rpm}$ and increases the current reference of the inner motor to see the change of the current reference of the outer motor. Then the current reference of the outer motor is adjusted automatically to maintain $360 \mathrm{rpm}$. The minimum copper loss points are coincided with the minimum copper loss curve which is obtained from (9) and (10).

Fig. 9 illustrates the phase currents of the single mode and the dual mode at the $360[\mathrm{rpm}]$ and $10[\mathrm{Nm}]$ load. The copper losses of single mode and the dual mode can be calculated as $93.2 \mathrm{~W}$ and $79.16 \mathrm{~W}$, respectively. Thus $14.04 \mathrm{~W}$ of the copper loss is decreased by using the proposed current distribution method.

Fig. 10 shows the comparison of the copper loss of the single mode and the dual mode with the proposed optimal current distribution method. As the load torque is increasing, the copper loss of the dual mode becomes lower than the single mode operation.

Fig. 11 shows the switching losses of the single and the dual mode operation. The switching frequency is $10 \mathrm{kHz}$ and the DC link voltage is $72 \mathrm{~V}$. The switching loss of the dual mode is larger than the single mode operation in the entire operating range which is expressed in (16). 


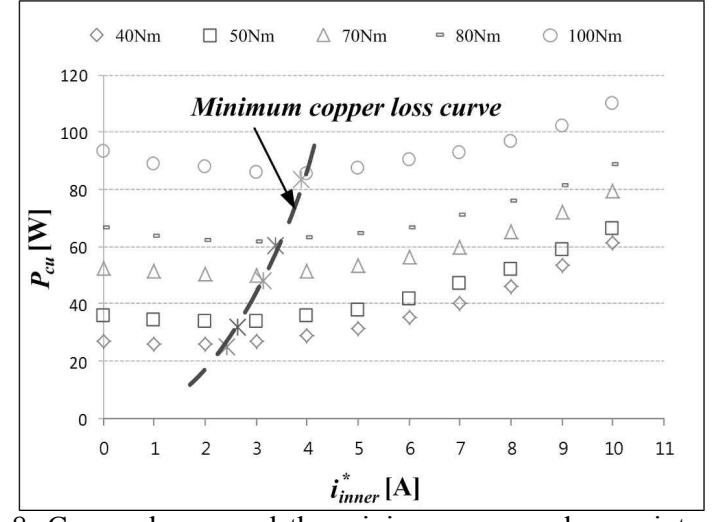

Fig. 8. Copper losses and the minimum copper loss point of the DR-BLDCM at the various load condition.

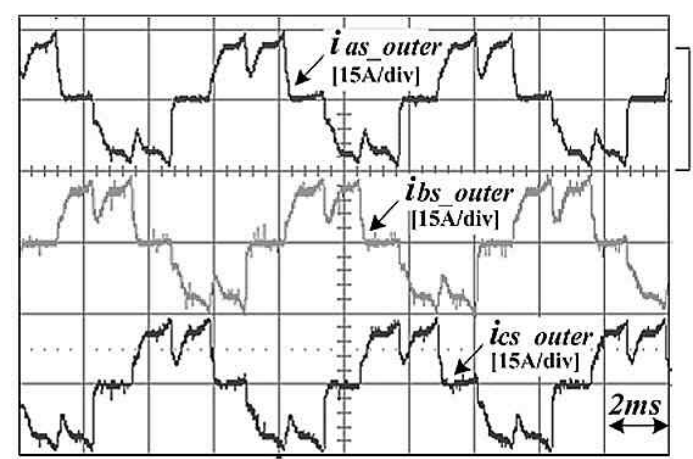

$30.53[\mathrm{~A}]$

(a)

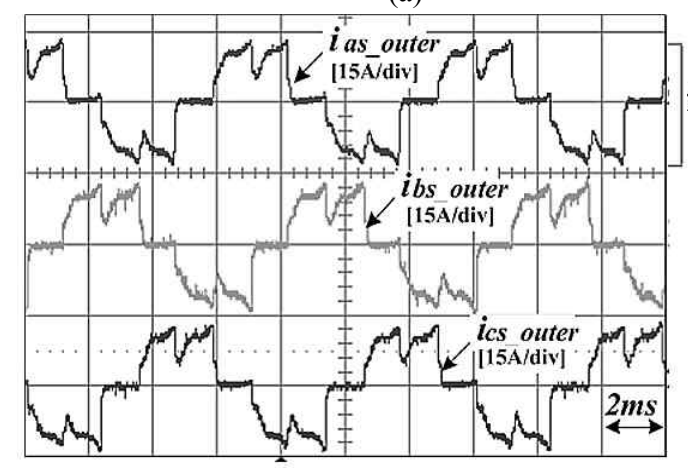

26.62[A]

(b)

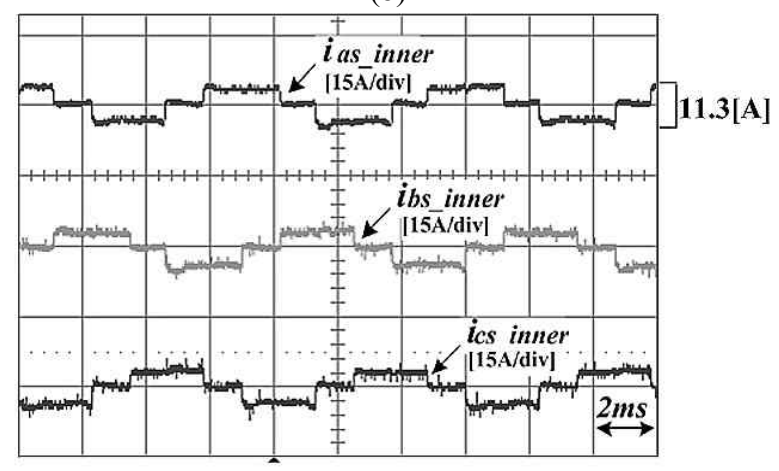

(c)

Fig. 9. Phase currents of the DR-BLDCM at 360[RPM]. (a) Phase currents of outer motor at single mode operation. (b) Phase currents of outer motor at dual mode operation. (c) Phase currents of inner motor at dual mode operation.
Fig. 12 shows the comparison of the total electrical losses of the single and dual mode operation at the various load torque. At the light load less than $3.3 \mathrm{Nm}$, the total electrical loss of the single mode is less than the dual mode operation. Thus, the single mode operation is suitable for this operating area. However, the difference of the total electrical losses between two modes is very small in this area, because the copper loss is dominant factor of the total electrical loss in low DC link voltage applications. In contrast, the total electrical loss of the dual mode is lower than the single mode if the load torque is higher than $3.3 \mathrm{Nm}$.

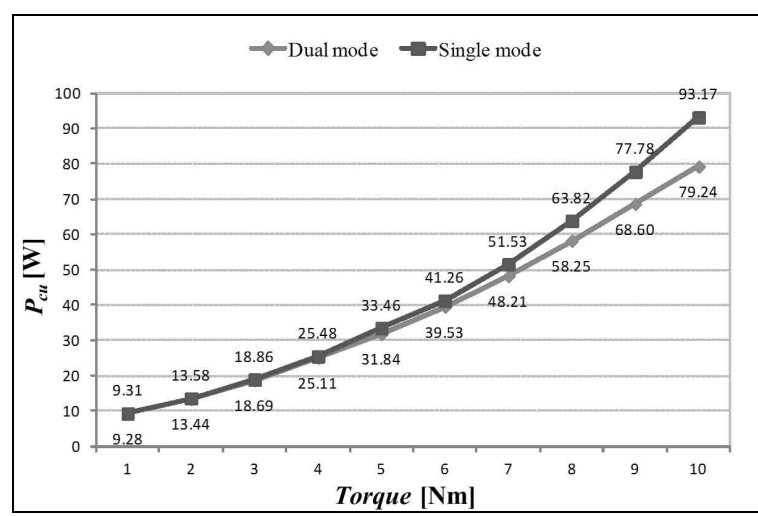

Fig. 10. Comparison of the copper loss of the single mode and the dual mode operation with optimal current distribution method.

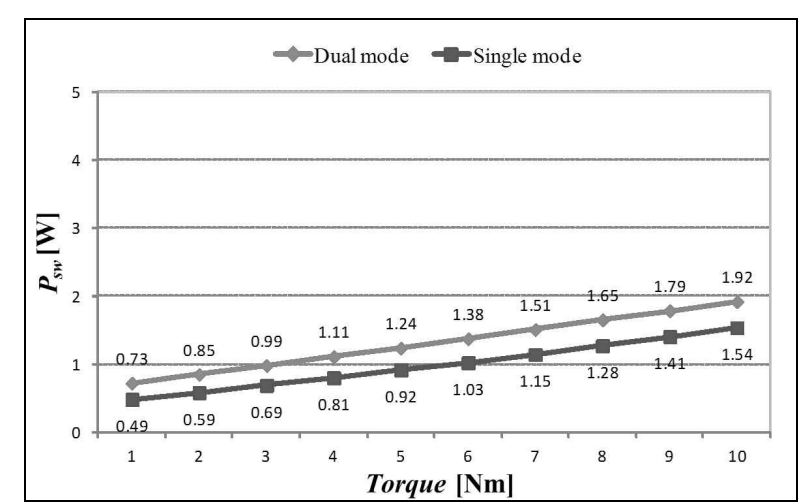

Fig. 11. Comparison of the switching loss of the single mode and the dual mode operation.

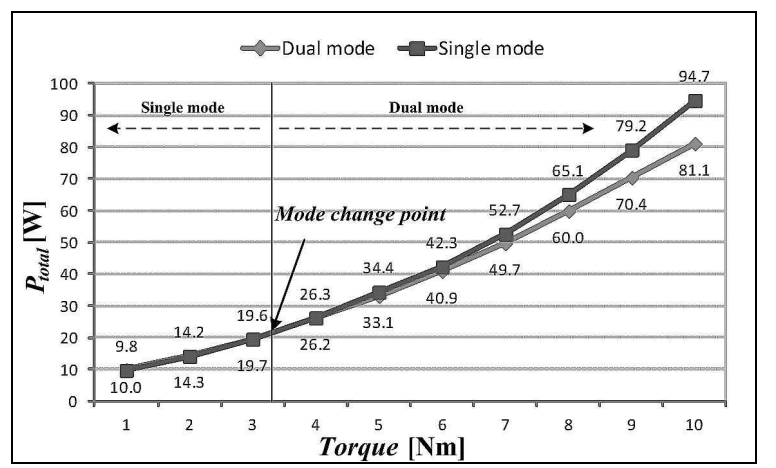

Fig. 12. Comparison of the total electrical losses of the single and dual mode operation at the various load torque. 


\section{CONCLUSIONS}

This paper proposed the optimal current distribution method of the DR-BLDCM for the minimum electrical loss. By considering the torque constant and stator resistance of the inner and the outer motors, the optimal current ratio was derived to minimize the copper loss. Moreover, the switching loss of the DR-BLDCM was analyzed to obtain the optimal mode change point for the electrical loss minimization. The proposed method can be easily applicable at the various operating condition by using the simple equation. The validity of the proposed current distribution method was verified through several experiments.

\section{REFERENCES}

[1] R. Qu and T. A. Lipo, "Dual-rotor, radial-flux, toroidally wound, permanent-magnet machines," IEEE Trans. Ind. Appl., Vol. 39, No. 6, pp. 1665-1673, Nov./Dec. 2003.

[2] D. Qin, R. Qu, and T. A. Lipo, "A novel electric machine employing torque magnification and flux concentration effects," IEEE-IAS Conf. Rec., Vol. 1, pp 132-139, 1999.

[3] M. M EL Missiry, "Theory and performance of double-stator hollow rotor motor," IEEE-IAS Conf. Rec., Vol. 1, pp. 760-767, 1987.

[4] T. A. Lipo, "Analog computer simulation of an axially aligned two rotor a.c. machine," Master's Thesis, Marquette University, Milwaukee, WI, August, 1964.

[5] D. H. Kelly, "Double-rotor induction motor," IEEE Trans. Power App. Syst., Vol. PAS-88, No. 7, pp. 1086-1092, Jul. 1969.

[6] B. Singh, P. Jain, A. P. Mittal, and J. R. P. Gupta, "Torque ripples minimization of DTC IPMSM drive for the EV propulsion system using a neural network," Journal of Power Electronics, Vol. 8, No. 1, pp. 23-34, Jan. 2008.

[7] J. Riveros, B. Bogado, J. Prieto, F. Barrero, S. Toral, and M. Jones, "Multiphase machines in propulsion drives of electric vehicles," in Proc. Power Electronics and Motion Control Conference (EPE/PEMC), pp. TS-T201, 2010.

[8] M. G. Simoes and P. Vieira Jr, "A high-torque low-speed multiphase brushless machine - A perspective application for electric vehicles," IEEE Trans. Ind. Electron., Vol. 49, No. 5, pp. 1154-1164, Oct. 2002.

[9] P. Zhao and G. Yang, "Torque density improvement of five-phase pmsm drive for electric vehicles applications," Journal of Power Electronics, Vol. 11, No .4, pp. 401-407, Jul. 2008.

[10] J. W. Park, S. H. Hwang, and J. M. Kim, "Sensorless Control of Brushless DC Motors With Torque Constant Estimation for Home Appliances," IEEE Trans. Ind. Appl., Vol. 48, No. 2, pp. 667-684, Mar./Apr. 2012.

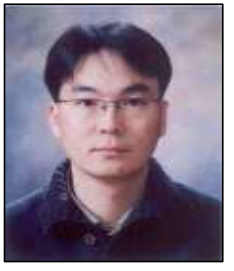

Sung-Jung Kim was born in Korea, in 1971. $\mathrm{He}$ received the B.S. and M.S. degrees in electrical engineering from Gyeongsang National University, Jinju, Korea, in 1996 and 2003, respectively. He is currently a Chief Research Engineer with Motor R\&D Department, LG Electronics. His research interests include the electromechanical design of brushless, synchronous and induction motors, with particular interest in drivers applications.

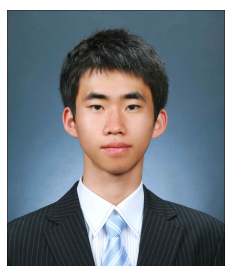

Je-Wook Park received the B.S. and M.S. degrees in electrical engineering from Pusan National University, Busan, Korea, in 2007 and 2009, respectively. $\mathrm{He}$ is currently working toward the Ph.D. degree at Pusan National University. His research interests include power conversion, electric machine drives and electric vehicle.

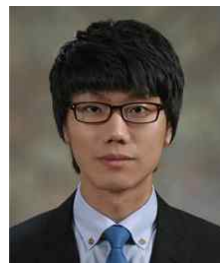

Won-Sang Im was born in Busan, Korea, in 1981. He received the B.S. and M.S. degrees in Electrical Engineering from Pusan National University, Busan, Korea, in 2007 and 2009, respectively, where he is currently working toward the Ph.D. degree. His research interests include power conversion, electric machine drives, and diagnosis and

fault-tolerance.

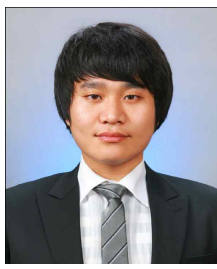

Hyun-Woo Jung was born in Korea, in 1982. He received the B.S. degree from Kyungpook National University, in 2009, and the M.S. degree in electrical engineering from Pusan National University, Busan, Korea, in 2012, respectively. He is currently working at the LG Electronics Energy Components BU Gaeumjeong-dong, Changwon City, Gyeongnam, 641-711, Korea. He does the research on motors in the home appliances development team.

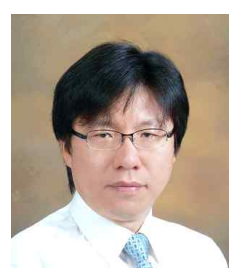

Jang-Mok Kim received the B.S. degree from Pusan National University (PNU), Korea, in 1988, and the M.S. and Ph.D. degrees from the Department of Electrical Engineering, Seoul National University, Seoul, Korea, in 1991 and 1996, respectively. From 1997 to 2000, he was a Senior Research Engineer with the Korea Electrical Power Research Institute (KEPRI). Since 2001, he has been with the School of Electrical Engineering, PNU, where he is currently a Research Member of the Research Institute of Computer Information and Communication, a Faculty Member, and a head of LG electronics Smart Control Center. As a Visiting Scholar, he joined the Center for Advanced Power Systems (CAPS), Florida State University, in 2007. His current interests include the control of electric machines, electric vehicle propulsion, and power quality. 